\title{
Effect of Soluble $\mathrm{P}_{2} \mathrm{O}_{5}$ Form on the Hydration and Hardening of Hemihydrate Phosphogypsum
}

\author{
Jianwu Zhang $\mathbb{D}^{D}$, Xiao Wang, Biao Jin, Chunguang Liu, Xiaoting Zhang, and Zhixin Li \\ School of Materials and Chemical Engineering, Henan University of Urban Construction, Pingdingshan 467036, China \\ Correspondence should be addressed to Jianwu Zhang; 20181023@hncj.edu.cn
}

Received 2 December 2021; Accepted 23 January 2022; Published 1 March 2022

Academic Editor: Michele Iafisco

Copyright (c) 2022 Jianwu Zhang et al. This is an open access article distributed under the Creative Commons Attribution License, which permits unrestricted use, distribution, and reproduction in any medium, provided the original work is properly cited.

\begin{abstract}
The preparation of building gypsum from phosphogypsum is one of the ways to realize its resource utilization. However, the precondition is first to reveal the influence mechanism of the impurities in phosphogypsum on the properties of plaster. Thus, the influence of the form of soluble $\mathrm{P}_{2} \mathrm{O}_{5}\left(\mathrm{H}_{3} \mathrm{PO}_{4}, \mathrm{H}_{2} \mathrm{PO}_{4}^{-}\right.$, and $\left.\mathrm{HPO}_{4}^{2-}\right)$ that is considered the most significant impurity on the hydration and hardening of hemihydrate phosphogypsum was studied in this paper, which included the setting time, mechanical properties, hydration rate, crystal structure, and micromorphology of hydration products. The results showed that both $\mathrm{H}_{3} \mathrm{PO}_{4}$ and $\mathrm{H}_{2} \mathrm{PO}_{4}^{-}$can accelerate the early hydration of hemihydrate phosphogypsum, shorten the setting time of paste, and improve the mechanical properties of hardened paste. In addition, $\mathrm{H}_{3} \mathrm{PO}_{4}$ had a more significant effect than $\mathrm{H}_{2} \mathrm{PO}_{4}^{-}$. Different from $\mathrm{H}_{3} \mathrm{PO}_{4}$ and $\mathrm{H}_{2} \mathrm{PO}_{4}^{-}, \mathrm{HPO}_{4}^{2-}$ significantly delayed the early hydration reaction of hemihydrate phosphogypsum, significantly prolonged the setting time of the paste, and significantly reduced the mechanical properties of the hardened body. The test data of XRD, IR, and SEM showed that two negative effects can be caused when soluble $\mathrm{P}_{2} \mathrm{O}_{5}$ existed in the form of $\mathrm{HPO}_{4}^{2-}$. On the one hand, $\mathrm{HPO}_{4}^{2-}$ can lead to the formation of $\mathrm{Ca}_{3}\left(\mathrm{PO}_{4}\right)_{2}$ insoluble substance in the hydration reaction of hemihydrate phosphogypsum, which significantly hindered the hydration reaction and prolonged the setting time of the paste. On the other hand, $\mathrm{HPO}_{4}^{2-}$ can change the crystallization habit of the hydration product of $\mathrm{CaSO}_{4} \cdot 2 \mathrm{H}_{2} \mathrm{O}$ and make it change from needle-columnar to semiflake and irregular shape, resulting in a significant reduction in the mechanical properties of hardened paste.
\end{abstract}

\section{Introduction}

Phosphogypsum is an industrial by-product produced in the process of wet production of phosphoric acid [1, 2]. According to statistics, 4-6 tons of phosphogypsum can be produced for each ton of phosphoric acid [3]. Currently, global emissions of phosphogypsum have exceeded 6 billion tons and are growing at about 150 million tons per year, according to relevant data. The annual output of phosphogypsum in China's phosphoric acid industry has exceeded 70 million tons, but the utilization ratio is only $40 \%$ according to China Phosphate and Compound Fertilizer Industry Association. The stock of phosphogypsum stockpiles has reached 5 hundred million tons in China at present, which not only occupies a lot of land resources but also causes serious environmental pollution to air, groundwater, and soil.
Similar to natural gypsum, the main chemical component of phosphogypsum is $\mathrm{CaSO}_{4} \cdot 2 \mathrm{H}_{2} \mathrm{O}$, which is usually over $90 \mathrm{wt}$. \%. The production of building gypsum is one of the main ways of resource utilization of phosphogypsum [4-7]. However, the application performance of phosphogypsum is often significantly inferior to that of natural gypsum due to harmful impurities such as $\mathrm{P}, \mathrm{F}$, and organic matter [8-13]. Therefore, to explore the influence of harmful impurities in phosphogypsum in order to implement effective impurity removal and purification is always a hot topic in the field of phosphogypsum research but is also one of the key issues in the efficient utilization of phosphogypsum resources.

Many studies have showed that phosphorus impurities have the greatest impact on the properties of hemihydrate phosphogypsum, among many types of impurities [14-16]. Phosphorus in phosphogypsum mainly exists in three forms: 
soluble $\mathrm{P}_{2} \mathrm{O}_{5}$, eutectic $\mathrm{P}_{2} \mathrm{O}_{5}$, and insoluble $\mathrm{P}_{2} \mathrm{O}_{5}$, among which soluble $\mathrm{P}_{2} \mathrm{O}_{5}$ has the most significant effect. Soluble $\mathrm{P}_{2} \mathrm{O}_{5}$ exists in four forms: $\mathrm{H}_{3} \mathrm{PO}_{4}, \mathrm{HPO}_{4}^{2-}, \mathrm{HPO}_{4}^{2-}$, and $\mathrm{PO}_{4}^{3-}$, which are produced by the ionization of phosphoric acid in an aqueous solution. Due to the high concentration of $\mathrm{Ca}^{2+}$ in gypsum and the low solubility of $\mathrm{Ca}_{3}\left(\mathrm{PO}_{4}\right)_{2}$ as an insoluble salt, the concentration of $\mathrm{PO}_{4}^{3-}$ in the system is low. Therefore, soluble $\mathrm{P}_{2} \mathrm{O}_{5}$ in phosphogypsum mainly exists in three forms: $\mathrm{H}_{3} \mathrm{PO}_{4}, \mathrm{HPO}_{4}^{2-}$, and $\mathrm{HPO}_{4}^{2-}$. Many studies have shown that the presence of soluble $\mathrm{P}_{2} \mathrm{O}_{5}$ can significantly hinder the hydration, condensation, and hardening process of hemihydrate phosphogypsum and reduce the strength of its hardened body [17-20]. The influence mechanism of soluble $\mathrm{P}_{2} \mathrm{O}_{5}$ is that it can combine with calcium ions in a liquid phase to produce insoluble calcium phosphate and cover the surface of gypsum particles, which hinders the hydration reaction of gypsum [21]. However, previous studies on the influence of soluble $\mathrm{P}_{2} \mathrm{O}_{5}$ on phosphogypsum performance often do not distinguish the form of soluble $\mathrm{P}_{2} \mathrm{O}_{5}$ since a single form of soluble $\mathrm{P}_{2} \mathrm{O}_{5}$ is difficult to separate from phosphogypsum, which is obviously not enough to help people fully understand the internal influence mechanism of soluble $\mathrm{P}_{2} \mathrm{O}_{5}$. In addition, most studies on the influence of soluble $\mathrm{P}_{2} \mathrm{O}_{5}$ on building phosphogypsum mainly focus on macroscopic properties, while there are still few studies on the influence mechanism of soluble $\mathrm{P}_{2} \mathrm{O}_{5}$ on the hydration rate of hemihydrate phosphogypsum and the crystal structure of hydration products.

Based on the above research deficiencies, this paper intended to study the influence of a soluble $\mathrm{P}_{2} \mathrm{O}_{5}$ form on the hydration reaction rate, crystal structure, and micromorphology characteristics of hemihydrate phosphogypsum by introducing different forms of soluble $\mathrm{P}_{2} \mathrm{O}_{5}$, establish the relationship between the hydration hardening characteristics of hemihydrate phosphogypsum and its physical and mechanical properties under the influence of soluble $\mathrm{P}_{2} \mathrm{O}_{5}$ form, and reveal the internal influence mechanism of soluble $\mathrm{P}_{2} \mathrm{O}_{5}$.

\section{Materials and Test Methods}

2.1. Materials. Phosphogypsum was purchased from Henan Qiangnai New Material Co., Ltd. Under laboratory conditions, phosphogypsum was washed with deionized water until neutrality to remove soluble impurities. The chemical composition of phosphogypsum before and after water washing is shown in Table 1 . It can be seen that phosphogypsum contained harmful impurities such as phosphorus and fluorine. After full water washing, the total $\mathrm{P}_{2} \mathrm{O}_{5}$ content in phosphogypsum decreased from $0.78 \%$ before water washing to $0.64 \%$, indicating that the soluble $\mathrm{P}_{2} \mathrm{O}_{5}$ content in phosphogypsum was $0.14 \%$. Phosphoric acid was bought from Yantai Shuangshuang Chemical Co., Ltd, which had a $\mathrm{H}_{3} \mathrm{PO}_{4}$ concentration of $85 \mathrm{wt}$. \%. The analytical pure reagents of $\mathrm{NaH}_{2} \mathrm{PO}_{4}$ and $\mathrm{Na}_{2} \mathrm{HPO}_{4}$ for the experiment were purchased from Tianjin Hengxing Chemical Reagent Co., Ltd. The polycarboxylic acid water reducer (PCE) was purchased from Shandong bock Chemical Co., Ltd. The deionized water was always used in the experiment.

\subsection{Test Methods}

2.2.1. Preparation of Hemihydrate Phosphogypsum. First, the washed phosphogypsum was dried at $40^{\circ} \mathrm{C}$ and then calcined at $150^{\circ} \mathrm{C}$ for $12 \mathrm{~h}$. Finally, the experimental hemihydrate phosphogypsum can be obtained after $7 \mathrm{~d}$ aging treatment of the calcined powder. According to the Chinese Standard GB/T9776-2008, the water consumption for a standard consistency of the hemihydrate phosphogypsum powder and its change with the content of PCE were determined, as shown in Table 2. The standard consistency of the experimental phosphogypsum is up to $97 \%$ water. The addition of PCE can effectively reduce the standard consistency of hemihydrate phosphogypsum. The water consumption for standard consistency of phosphogypsum is significantly reduced to $71 \%$ when the optimum PCE content is $0.8 \%$.

2.2.2. Setting Time and Mechanical Property Test. First, in order to investigate the influence of the soluble $\mathrm{P}_{2} \mathrm{O}_{5}$ form on the setting time and mechanical properties of hemihydrate phosphogypsum, the content of $\mathrm{H}_{3} \mathrm{PO}_{4}, \mathrm{NaH}_{2} \mathrm{PO}_{4}$, and $\mathrm{Na}_{2} \mathrm{HPO}_{4}$ was determined to be $0.23 \%, 0.24 \%$, and $0.28 \%$, respectively, according to the content of soluble $\mathrm{P}_{2} \mathrm{O}_{5}$ in phosphogypsum before and after washing. Second, each form of the soluble $\mathrm{P}_{2} \mathrm{O}_{5}$ reagent was weighed and predissolved to the mixing water measured by $71 \mathrm{wt}$. \% of the standard water consumption for consistency at the optimal dosage of PCE. Then, the hemihydrate phosphogypsum was added to the mixing water and stirred to make a uniform paste. The initial setting time and final setting time of paste were measured by the vicar apparatus. The prepared paste was molded into blocks of $40 \mathrm{~mm} \times 40 \mathrm{~mm} \times 160 \mathrm{~mm}$. After $1 \mathrm{~d}$ age, the wet flexural strength and wet compressive strength of each hardened paste were tested. At the same time, parts of the formed samples were dried in an oven at $40^{\circ} \mathrm{C}$ until they were completely dried, which was used for the test of dry flexural and dry compressive strength of the hardened paste. The samples with $\mathrm{H}_{3} \mathrm{PO}_{4}, \mathrm{NaH}_{2} \mathrm{PO}_{4}$, and $\mathrm{Na}_{2} \mathrm{HPO}_{4}$ were named $\mathrm{P}-\mathrm{H}_{3} \mathrm{PO}_{4}, \mathrm{P}-\mathrm{H}_{2} \mathrm{PO}_{4}^{-}$, and $\mathrm{P}-\mathrm{HPO}_{4}^{2-}$, respectively. The sample without the soluble $\mathrm{P}_{2} \mathrm{O}_{5}$ reagent was marked as control.

2.2.3. Hydration Degree Test. According to the method described in Section 2.2.2, each sample pastes were prepared. After reaching the specified age, the hydration was stopped immediately with anhydrous ethanol for $24 \mathrm{~h}$, and then the samples were dried in an oven at $40^{\circ} \mathrm{C}$. Finally, the dried samples were placed in an oven at $250^{\circ} \mathrm{C}$ for low-temperature heat treatment to constant weight. According to the mass loss of the sample before and after heat treatment, the content of crystal water was calculated to characterize the hydration degree of the sample.

2.2.4. XRD, IR, and SEM Tests. After the dry strength test, the fractured sample was used for XRD, IR, and SEM characterization. The phase composition and structure of 
TABLE 1: Chemical composition of phosphogypsum before and after water washing.

\begin{tabular}{lccccccccc}
\hline Condition & $\mathrm{CaO}$ & $\mathrm{Fe}_{2} \mathrm{O}_{3}$ & $\mathrm{Al}_{2} \mathrm{O}_{3}$ & $\mathrm{~F}$ & $\mathrm{SO}_{3}$ & $\mathrm{SiO}_{2}$ & $\mathrm{P}_{2} \mathrm{O}_{5}$ & $\mathrm{R} 2 \mathrm{O}$ & $\mathrm{MgO}$ \\
\hline Before washing & 38.28 & 0.58 & 1.50 & 0.35 & 48.25 & 8.75 & 0.78 & 0.95 & 0.19 \\
After washing & 39.49 & 0.23 & 1.36 & 0.345 & 49.12 & 7.51 & 0.64 & 0.84 & 0.14 \\
\hline
\end{tabular}

TABle 2: Test results of water consumption for standard consistency.

\begin{tabular}{lcccccc}
\hline PCE dosage (\%) & 0 & 0.2 & 0.4 & 0.6 & 0.8 & 1.0 \\
\hline Water for standard consistency (wt\%) & 97 & 82 & 74 & 72 & 71 & 71 \\
\hline
\end{tabular}

hydration product crystals of each sample were tested by a Bruker D8 Advance X-ray diffractometer. The test range was $5-50^{\circ}$ at a scanning rate of $0.02^{\circ} / \mathrm{min}$. The infrared spectrum data of each hydration sample were collected by the Fourier infrared absorption spectrometer with the model of Nicolet SDX CFTIR. After the fractured samples were coated with gold, the SEM images were captured on a Quanta-450 SEM at $15 \mathrm{kV}$.

\section{Results and Discussion}

3.1. Setting Time. Figure 1 shows the effect of the soluble $\mathrm{P}_{2} \mathrm{O}_{5}$ form on the setting time of building phosphogypsum. For the control sample, the initial setting time and final setting time were $11 \mathrm{~min}$ and $17 \mathrm{~min}$, respectively. The addition of $\mathrm{H}_{3} \mathrm{PO}_{4}$ can significantly accelerate the setting and hardening rate of the paste, and the initial setting time and final setting time were shortened to $7 \mathrm{~min}$ and $12 \mathrm{~min}$, respectively. Similar to $\mathrm{H}_{3} \mathrm{PO}_{4}$, the addition of $\mathrm{H}_{2} \mathrm{PO}_{4}^{-}$can also promote the setting and hardening of the paste, but its effect is less than that of $\mathrm{H}_{3} \mathrm{PO}_{4}$. Different from the effect of soluble $\mathrm{P}_{2} \mathrm{O}_{5}$ in the form of $\mathrm{H}_{3} \mathrm{PO}_{4}$ and $\mathrm{H}_{2} \mathrm{PO}_{4}^{-}$, the addition of $\mathrm{HPO}_{4}^{2-}$ significantly delayed the setting and hardening rate of paste. The test data showed that the initial setting time and final setting time of $\mathrm{P}-\mathrm{HPO}_{4}^{2-}$ sample were significantly prolonged to $21 \mathrm{~min}$ and $27 \mathrm{~min}$, respectively, compared with the control sample.

3.2. Mechanical Properties. Figure 2 shows the effect of different forms of soluble $\mathrm{P}_{2} \mathrm{O}_{5}$ on the compressive strength of hemihydrate phosphogypsum. For the control sample, the wet compressive strength and dry compressive strength of hardened pastes were $3.8 \mathrm{MPa}$ and $6.8 \mathrm{MPa}$, respectively. After the addition of $\mathrm{H}_{3} \mathrm{PO}_{4}$, the wet compressive strength and dry compressive strength of hardened paste increased to 5.3 $\mathrm{MPa}$ and 9.5 MPa, respectively, which increased by $39.5 \%$ and $39.7 \%$ compared with the control sample, respectively. The addition of $\mathrm{H}_{2} \mathrm{PO}_{4}{ }^{-}$also can improve the compressive strength of hemihydrate phosphogypsum, but the effect was not as significant as $\mathrm{H}_{3} \mathrm{PO}_{4}$. The wet compressive strength and dry compressive strength of the $\mathrm{P}-\mathrm{H}_{2} \mathrm{PO}_{4}^{-}$sample increased by $28.9 \%$ and $25 \%$, respectively, compared with the control sample. Different from $\mathrm{H}_{3} \mathrm{PO}_{4}$ and $\mathrm{H}_{2} \mathrm{PO}_{4}^{-}$, the addition of $\mathrm{HPO}_{4}^{2-}$ significantly reduced the strength of hemihydrate phosphogypsum. The data showed that the wet compressive strength and dry compressive strength of the
$\mathrm{P}-\mathrm{HPO}_{4}^{2-}$ sample were only $3.6 \mathrm{MPa}$ and $3.1 \mathrm{MPa}$, respectively, which were reduced by $5.3 \%$ and $20.5 \%$, respectively, compared with the control sample. Figure 3 shows the flexural strength test results. It can be seen that the variation law of flexural strength and compressive strength was similar. Similarly, the addition of $\mathrm{H}_{3} \mathrm{PO}_{4}$ and $\mathrm{H}_{2} \mathrm{PO}_{4}^{-}$can improve the wet and dry flexural strength of hemihydrate phosphogypsum, and the effect of $\mathrm{H}_{3} \mathrm{PO}_{4}$ is more significant than $\mathrm{H}_{2} \mathrm{PO}_{4}^{-}$. The addition of $\mathrm{HPO}_{4}^{2-}$ can significantly reduce the flexural strength of the hardened paste.

3.3. Hydration Degree. The effect of different forms of $\mathrm{P}_{2} \mathrm{O}_{5}$ on the crystalline water content of hemihydrate phosphogypsum is shown in Figure 4. It can be seen that, in the initial hydration stage, the form soluble $\mathrm{P}_{2} \mathrm{O}_{5}$ of $\mathrm{H}_{3} \mathrm{PO}_{4}$ and $\mathrm{H}_{2} \mathrm{PO}_{4}^{-}$ can effectively accelerate the hydration reaction of hemihydrate phosphogypsum, and the role of $\mathrm{H}_{3} \mathrm{PO}_{4}$ in promoting hydration is significantly higher than that of $\mathrm{H}_{2} \mathrm{PO}_{4}^{-}$. Different from $\mathrm{H}_{3} \mathrm{PO}_{4}$ and $\mathrm{H}_{2} \mathrm{PO}_{4}^{-}$, soluble $\mathrm{P}_{2} \mathrm{O}_{5}$ in the form of $\mathrm{HPO}_{4}^{2-}$ can significantly delay the early hydration reaction of the hemihydrate phosphogypsum. For example, after hydration for $30 \mathrm{~min}$, the content of crystal water in $\mathrm{P}_{-} \mathrm{H}_{3} \mathrm{PO}_{4}$ and $\mathrm{P}-\mathrm{H}_{2} \mathrm{PO}_{4}^{-}$samples was $18.1 \%$ and $16.4 \%$, respectively, which was significantly higher than of the control sample. However, the crystalline water content of $\mathrm{P}-\mathrm{HPO}_{4}^{2-}$ sample was only $12.3 \%$ at this time, which was significantly lower than that of the control sample. After $24 \mathrm{~h}$ hydration, the crystal water content of each sample was similar, which was close to the theoretical crystal water content of dihydrate gypsum crystals, indicating that the hemihydrate gypsum in each sample has been completely hydrated. By comparing the data in Figures 2 and 5, it can be seen that the effect of soluble $\mathrm{P}_{2} \mathrm{O}_{5}$ form on the hydration rate of hemihydrate phosphogypsum was consistent with its effect on the setting time.

3.4. XRD Analysis. Figure 5 shows the XRD spectrum of each hydration sample. It can be seen that the hydration products of each 9 are calcium sulfate dihydrate crystals. Moreover, the peak shape of the diffraction peak in each sample was very sharp, which indicated that the crystal crystallization degree of the hydration products of dihydrate gypsum in each sample was high. The difference was that the peak intensity of the three strong peaks of dihydrate gypsum crystal in the $\mathrm{P}-\mathrm{H}_{3} \mathrm{PO}_{4}$ sample was significantly lower than that of the control, $\mathrm{P}-\mathrm{H}_{2} \mathrm{PO}_{4}^{-}$, and $\mathrm{P}-\mathrm{HPO}_{4}^{2-}$ samples. Generally speaking, the intensity of the crystal diffraction peak was directly proportional to the number of crystals and crystallinity. According to the test results of the hydration rate, the amount of the dihydrate gypsum crystal in each 


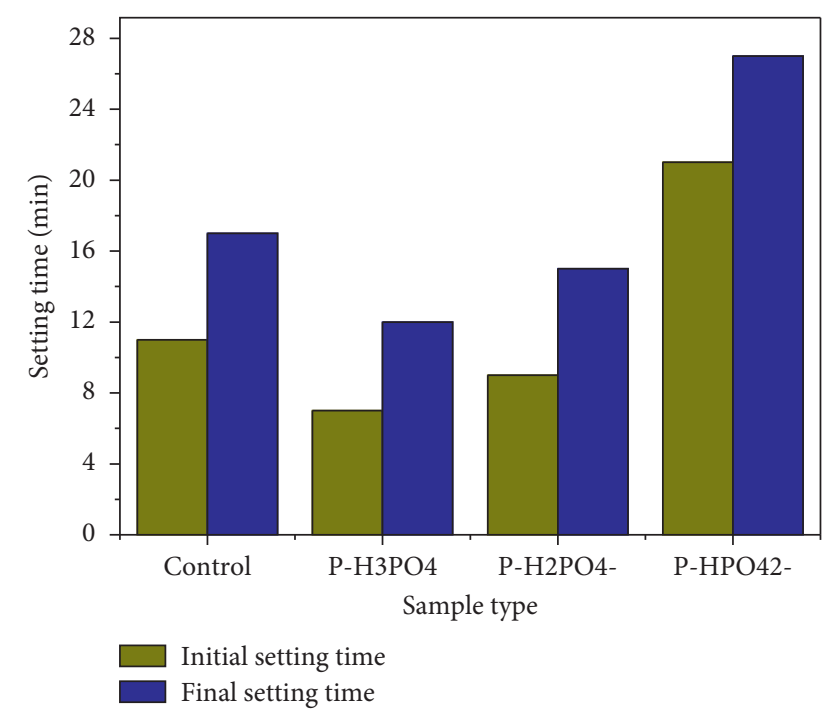

FIgURE 1: Influence of soluble $\mathrm{P}_{2} \mathrm{O}_{5}$ form on setting time of hemihydrate phosphogypsum.

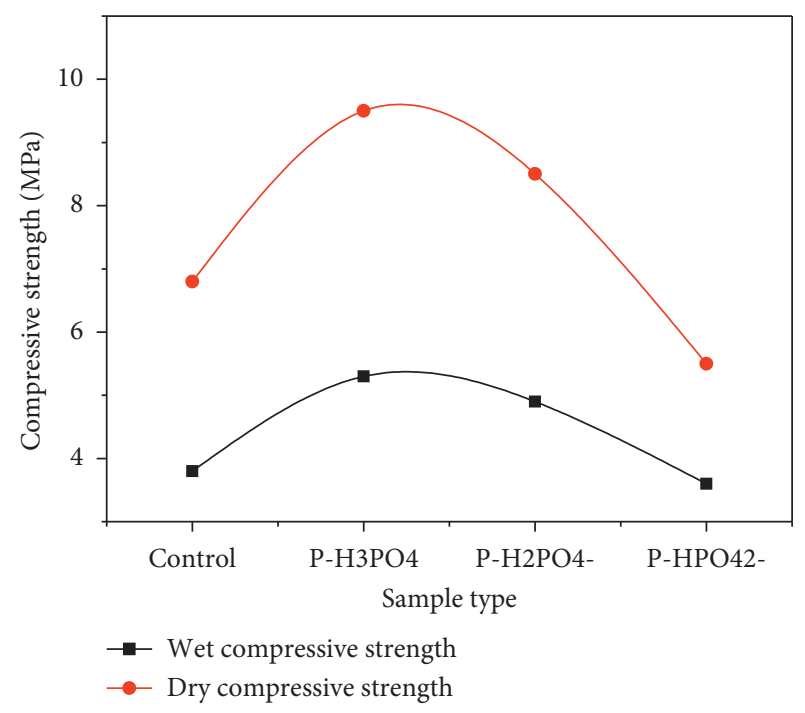

Figure 2: Influence of soluble $\mathrm{P}_{2} \mathrm{O}_{5}$ form on the compressive strength of hemihydrate phosphogypsum.

sample was the same after $1 \mathrm{~d}$ hydration. Therefore, it can be inferred that the existence of soluble $\mathrm{P}_{2} \mathrm{O}_{5}$ may affect the hydration crystallization process of hemihydrate phosphogypsum and then significantly change the crystallization degree of the crystal surface corresponding to the three strong peaks in dihydrate gypsum crystals.

In order to further explain the influence of soluble $\mathrm{P}_{2} \mathrm{O}_{5}$, the (020) crystal plane diffraction peak was taken as the research object for in-depth analysis and description, as shown in Figure 6. It can be seen that the diffraction angles of the crystal plane diffraction peaks of each sample (020) were different. Through the peak seeking function of jade analysis software, the diffraction angles of (020) crystal plane of the control sample, $\mathrm{P}-\mathrm{H}_{3} \mathrm{PO}_{4}, \mathrm{P}-\mathrm{H}_{2} \mathrm{PO}_{4}^{-}$, and $\mathrm{P}-\mathrm{HPO}_{4}^{2-}$ can be determined to be $11.63^{\circ}, 11.585^{\circ}, 11.643^{\circ}$, and $11.679^{\circ}$, respectively. This phenomenon may be caused by the formation of $\mathrm{CaHPO}_{4} \cdot 2 \mathrm{H}_{2} \mathrm{O}$ solid solution in a dihydrate gypsum crystal due to the existence of soluble $\mathrm{P}_{2} \mathrm{O}_{5}$. Many studies showed that $\mathrm{CaHPO}_{4} \cdot 2 \mathrm{H}_{2} \mathrm{O}$ and $\mathrm{CaSO}_{4} \cdot 2 \mathrm{H}_{2} \mathrm{O}$ belong to a monoclinic system and have relatively similar lattice constants. Therefore, $\mathrm{CaHPO}_{4} \cdot 2 \mathrm{H}_{2} \mathrm{O}$ can enter the $\mathrm{CaSO}_{4} \cdot 2 \mathrm{H}_{2} \mathrm{O}$ lattice to form a solid solution under certain conditions. In order to facilitate the analysis, the diffraction angles of the diffraction peaks of the (020) crystal plane of pure $\mathrm{CaSO}_{4} \cdot 2 \mathrm{H}_{2} \mathrm{O}$ and pure $\mathrm{CaHPO}_{4} \cdot 2 \mathrm{H}_{2} \mathrm{O}$ are calibrated in Figure 6 , which were $11.588^{\circ}$ and $11.68^{\circ}$, respectively. For the control sample, the diffraction angle of (020) crystal plane was between $\mathrm{CaSO}_{4} \cdot 2 \mathrm{H}_{2} \mathrm{O}$ and $\mathrm{CaHPO}_{4} \cdot 2 \mathrm{H}_{2} \mathrm{O}$ crystals. It can be seen that there was a solid solution of $\mathrm{CaHPO}_{4} \cdot 2 \mathrm{H}_{2} \mathrm{O}$ in the hydration process of the control sample. The source of $\mathrm{CaHPO}_{4} \cdot 2 \mathrm{H}_{2} \mathrm{O}$ in the control sample was mainly related to its eutectic phosphorus. Relevant research studies showed that the eutectic $\mathrm{P}_{2} \mathrm{O}_{5}$ still existed when phosphogypsum was calcined at $150^{\circ} \mathrm{C}$. Therefore, when hemihydrate phosphogypsum reacted with water, part of $\mathrm{HPO}_{4}^{2-}$ dissolved from its lattice may reparticipate in the crystallization process of dihydrate gypsum. For the $\mathrm{P}-\mathrm{H}_{3} \mathrm{PO}_{4}$ sample, the diffraction angle of the (020) crystal plane was very close to that of pure $\mathrm{CaSO}_{4} \cdot 2 \mathrm{H}_{2} \mathrm{O}$. This may be due to the fact that $\mathrm{H}_{3} \mathrm{PO}_{4}$ was difficult to deeply ionize and produce more $\mathrm{HPO}_{4}{ }^{2-}$ ions in the reaction liquid phase as a weak electrolyte, which resulted in the crystal surface diffraction peak site of $\mathrm{P}_{-} \mathrm{H}_{3} \mathrm{PO}_{4}$ being closer to pure $\mathrm{CaSO}_{4} \cdot 2 \mathrm{H}_{2} \mathrm{O}$. For $\mathrm{P}_{-} \mathrm{H}_{2} \mathrm{PO}_{4}{ }^{-}$, the shift of diffraction peak position to the right may also be related to the significant ionization of $\mathrm{H}_{2} \mathrm{PO}_{4}{ }^{-}$ions. For $\mathrm{P}-\mathrm{HPO}_{4}^{2-}$, the directly doped $\mathrm{HPO}_{4}^{2-}$ ions can significantly participate in the formation of calcium sulfate dihydrate, resulting in the crystal diffraction peak position more inclined to the direction of $\mathrm{CaHPO}_{4} \cdot 2 \mathrm{H}_{2} \mathrm{O}$.

Accordingly, the eutectic phenomenon in the control sample, $\mathrm{P}_{-} \mathrm{H}_{2} \mathrm{PO}_{4}^{-}$, and $\mathrm{P}-\mathrm{HPO}_{4}^{2-}$ significantly inhibited the growth of gypsum crystals along the c-axis and relatively increased the growth rate and crystallinity of (020) crystal planes, which resulted in the diffraction peak intensity of (020) crystal planes in these three groups being significantly higher than that of $\mathrm{P}_{-} \mathrm{H}_{3} \mathrm{PO}_{4}$.

3.5. IR Analysis. In order to further analyze the influence mechanism of the form of soluble $\mathrm{P}_{2} \mathrm{O}_{5}$, the infrared spectrum data of each hydration sample were tested, as shown in Figure 7. The stretching vibration peaks of crystalline water hydroxyl in calcium sulfate dihydrate were detected near $3547 \mathrm{~cm}^{-1}$ and $3045 \mathrm{~cm}^{-1}$. The peak near $1685 \mathrm{~cm}^{-1}$ and $1621 \mathrm{~cm}^{-1}$ was the bending vibration peak of $\mathrm{S}-\mathrm{O}$ in $\mathrm{CaSO}_{4}$. For the sample of control, $\mathrm{P}-\mathrm{H}_{2} \mathrm{PO}_{4}^{-}$, and $\mathrm{P}-\mathrm{HPO}_{4}^{2-}$, the characteristic absorption peak of eutectic phosphorus was also detected near $845 \mathrm{~cm}^{-1}$, which was consistent with the analysis results of XRD. In addition, the characteristic absorption peak of $\mathrm{PO}_{4}^{3-}$ was also detected near $1036 \mathrm{~cm}^{-1}$ in control and $\mathrm{P}-\mathrm{HPO}_{4}^{2-}$ sample, indicating that insoluble $\mathrm{Ca}_{3}\left(\mathrm{PO}_{4}\right)_{2}$ was generated in the hydration process of these two groups of samples. The reason why the control sample and $\mathrm{P}-\mathrm{HPO}_{4}^{2-}$ sample had a longer setting time than other group may be related to this phenomenon. 


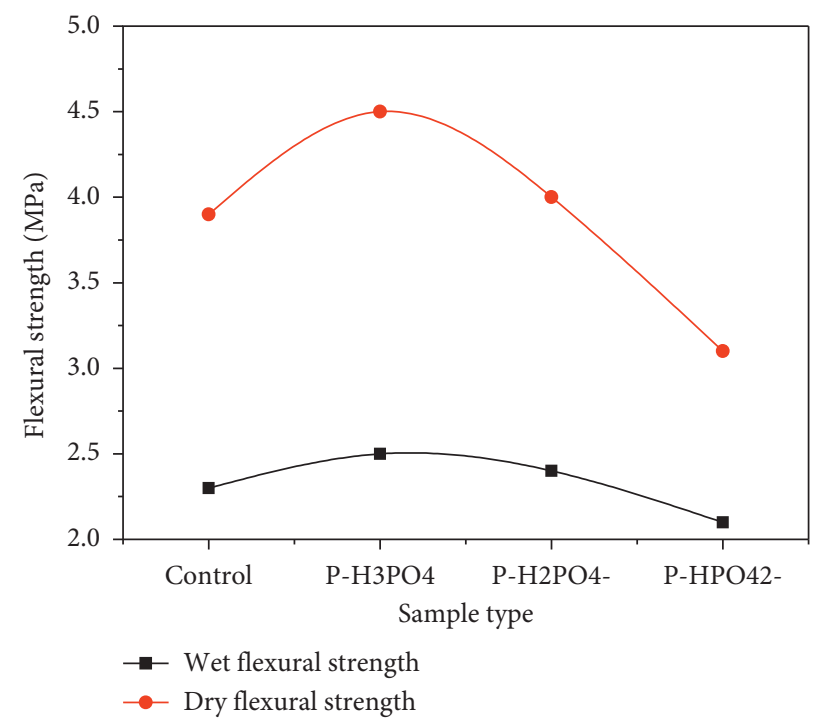

FIgURE 3: Influence of soluble $\mathrm{P}_{2} \mathrm{O}_{5}$ form on the flexural strength of hemihydrate phosphogypsum.

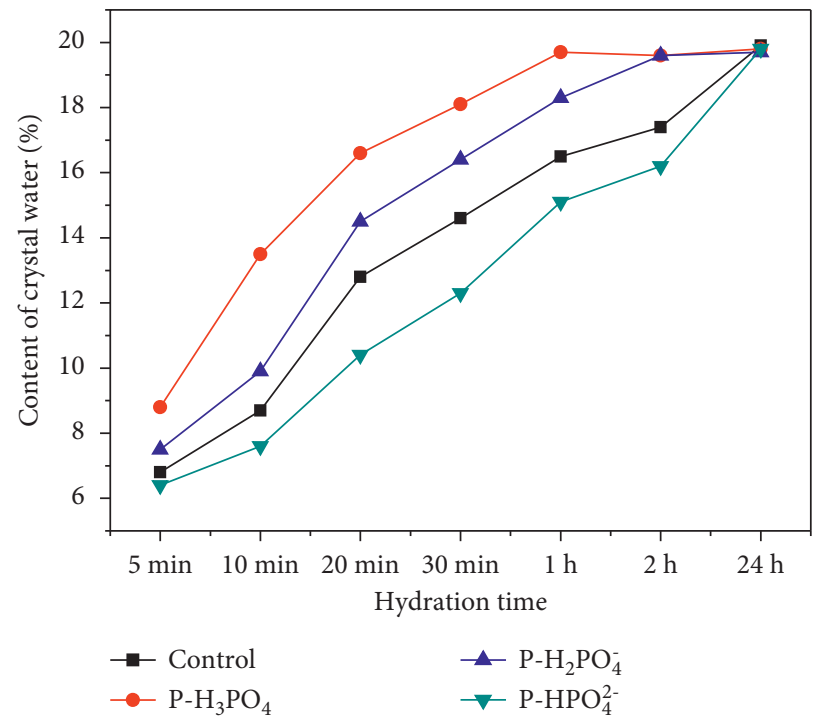

FIGURE 4: Influence of soluble $\mathrm{P}_{2} \mathrm{O}_{5}$ form on the content of water of crystallization of hemihydrate phosphogypsum at different hydration times.

Many studies have proved that the formation of $\mathrm{Ca}_{3}\left(\mathrm{PO}_{4}\right)_{2}$ can effectively cover the surface of hemihydrate gypsum crystal and delay its hydration process [21, 22].

3.6. Scanning Electron Microscopy. Figure 8 shows the microtopography photograph of each sample. For the control sample, the hydrated dihydrate gypsum crystal mainly showed a coarse columnar structure, and a part of the form of the product was irregular plate. In addition, there was an obvious parallel superposition between the columnar crystal products. Obviously different from the control sample, the dihydrate gypsum crystal formed in the $\mathrm{P}-\mathrm{H}_{3} \mathrm{PO}_{4}$ sample was significantly needle columnar, and each crystal showed a high degree of overlapping and interleaving, which reflected relatively higher strength of the hardened body. For the $\mathrm{P}-\mathrm{H}_{2} \mathrm{PO}_{4}^{-}$sample, the morphology of hydration products was mainly a needle column and an irregular shape. The crystal morphology of hydration products in the $\mathrm{P}-\mathrm{HPO}_{4}^{2-}$ sample was mostly plate-like or irregular, and only a few crystals were columnar. These morphological characteristics significantly affect the crystal 


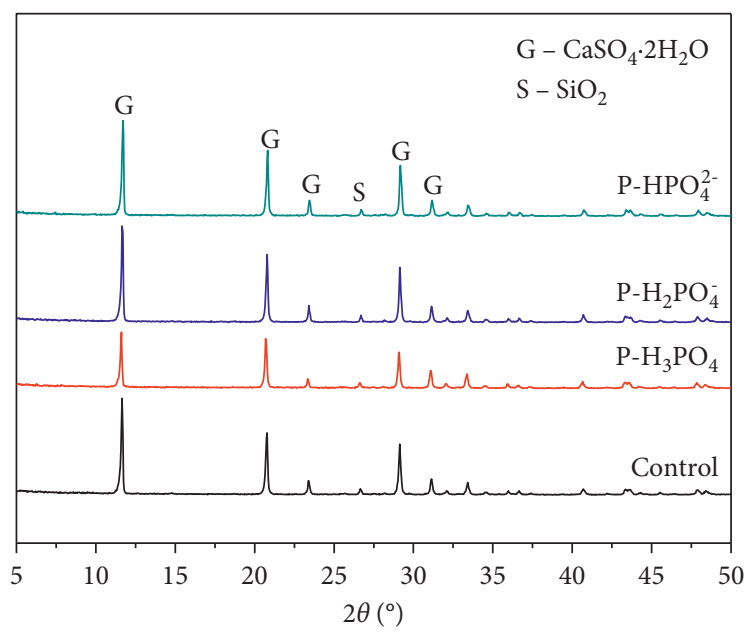

FIGURE 5: XRD spectra of each sample.

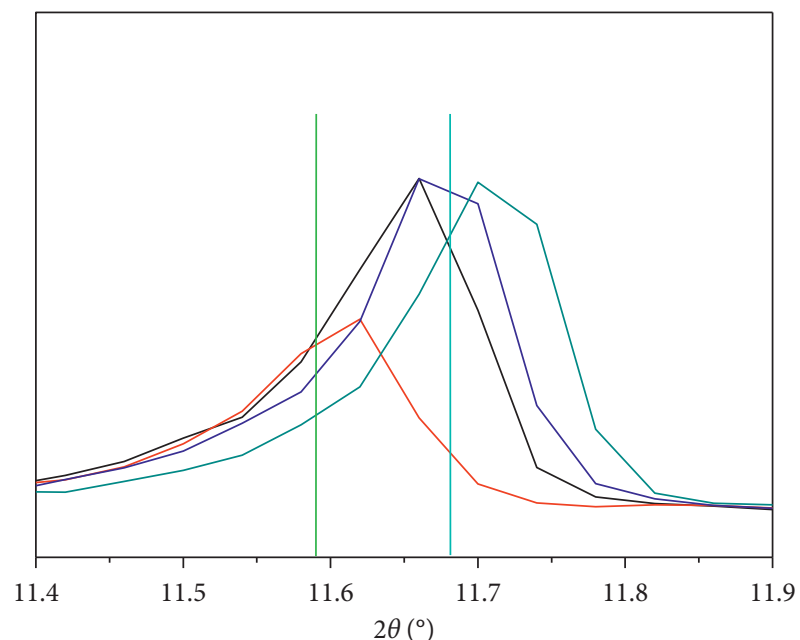

Position of (020) crystal plane diffraction peak of $\mathrm{CaSO}_{4} \cdot 2 \mathrm{H}_{2} \mathrm{O}$

— Position of (020) crystal plane diffraction peak of $\mathrm{CaHPO}_{4} \cdot 2 \mathrm{H}_{2} \mathrm{O}$

- Control

$-\mathrm{H}_{3} \mathrm{PO}_{4}$

$-\mathrm{H}_{2} \mathrm{PO}_{4}^{-}$

$-\mathrm{HPO}_{4}^{2-}$

Figure 6: X-ray diffraction peak of the (020) crystal plane of $\mathrm{CaSO}_{4} \cdot 2 \mathrm{H}_{2} \mathrm{O}$ in each sample.

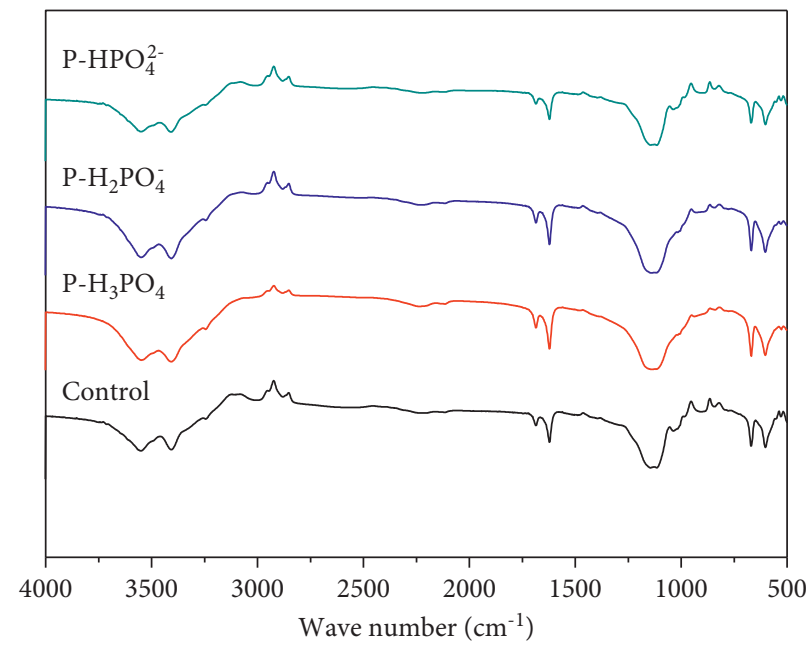

Figure 7: Infrared spectra of each sample. 


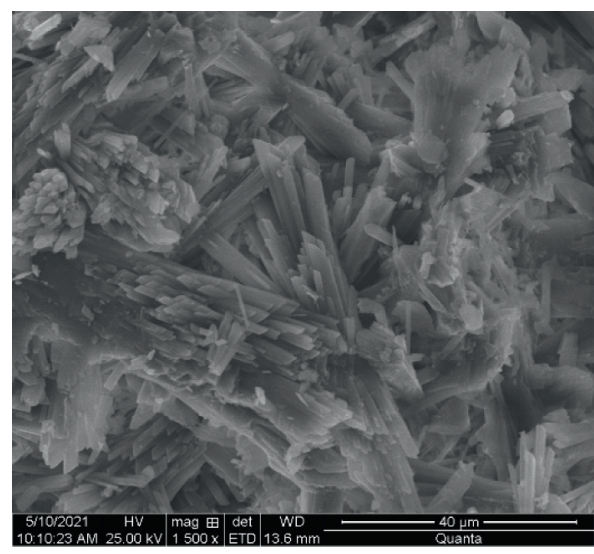

(a)

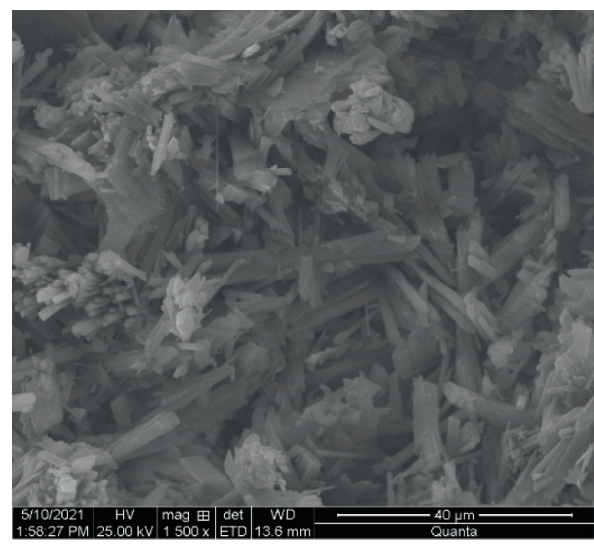

(c)

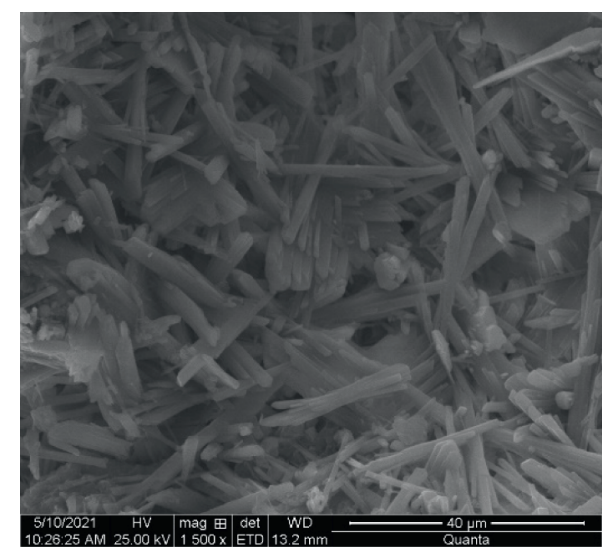

(b)

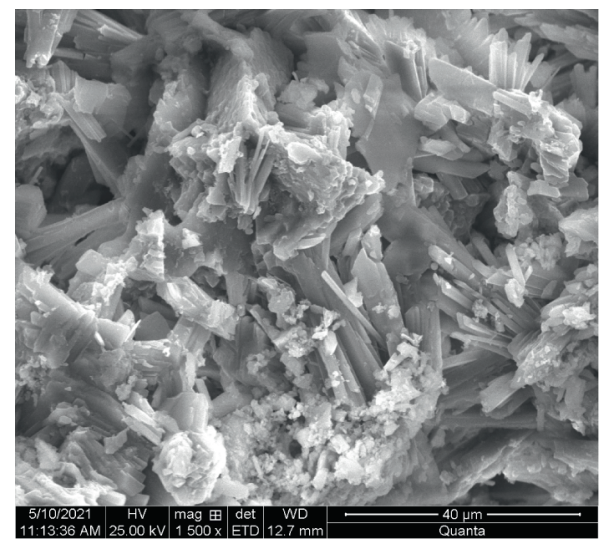

(d)

Figure 8: Microscopic morphologies of each sample: (a) control; (b) $\mathrm{P}_{3} \mathrm{H}_{3} \mathrm{PO}_{4}$; (c) $\mathrm{P}-\mathrm{H}_{2} \mathrm{PO}_{4}^{-}$; (d) $\mathrm{P}-\mathrm{HPO}_{4}^{2-}$.

skeleton effect of dihydrate gypsum in the $\mathrm{P}-\mathrm{HPO}_{4}{ }^{2-}$ sample, resulting in significantly poor mechanical properties of its hardened body.

\section{Conclusions}

This paper mainly studies the influence of soluble $\mathrm{P}$ in three forms of $\mathrm{H}_{3} \mathrm{PO}_{4}, \mathrm{H}_{2} \mathrm{PO}_{4}^{-}$, and $\mathrm{HPO}_{4}^{2-}$ on the hydration and hardening of hemihydrate phosphogypsum. The main conclusions were as follows:

(1) Soluble $\mathrm{P}_{2} \mathrm{O}_{5}$ in the form of $\mathrm{H}_{3} \mathrm{PO}_{4}$ and $\mathrm{H}_{2} \mathrm{PO}_{4}^{-}$can effectively accelerate the early hydration reaction of hemihydrate phosphogypsum, and the influence of $\mathrm{H}_{3} \mathrm{PO}_{4}$ was greater than that of $\mathrm{H}_{2} \mathrm{PO}_{4}^{-}$. Accordingly, the setting time of paste with soluble $\mathrm{P}_{2} \mathrm{O}_{5}$ in the form of $\mathrm{H}_{3} \mathrm{PO}_{4}$ and $\mathrm{H}_{2} \mathrm{PO}_{4}^{-}$was significantly shortened, and similarly, the effect of $\mathrm{H}_{3} \mathrm{PO}_{4}$ was more significant than that of $\mathrm{H}_{2} \mathrm{PO}_{4}^{-}$. Different from $\mathrm{H}_{3} \mathrm{PO}_{4}$ and $\mathrm{H}_{2} \mathrm{PO}_{4}^{-}, \mathrm{HPO}_{4}^{2-}$ significantly hindered the early hydration reaction and prolonged the setting time of hemihydrate phosphogypsum.

(2) The test results of mechanical properties showed that when the soluble $\mathrm{P}_{2} \mathrm{O}_{5}$ in phosphogypsum mainly existed in the form of $\mathrm{H}_{3} \mathrm{PO}_{4}$ and $\mathrm{H}_{2} \mathrm{PO}_{4}^{-}$, the mechanical properties of building phosphogypsum can be improved to a certain extent, and the enhancement effect of $\mathrm{H}_{3} \mathrm{PO}_{4}$ on the mechanical properties of hardened paste was higher than that of $\mathrm{H}_{2} \mathrm{PO}_{4}^{-}$. On the contrary, soluble $\mathrm{P}_{2} \mathrm{O}_{5}$ with $\mathrm{HPO}_{4}^{2-}$ as the main form had a significant negative effect on the mechanical properties of hemihydrate phosphogypsum.

(3) The test results of XRD, IR, and SEM comprehensively reflected that two negative effects can be caused when the soluble $\mathrm{P}_{2} \mathrm{O}_{5}$ in phosphogypsum exists in the form of $\mathrm{HPO}_{4}^{2-}$. On the one hand, $\mathrm{HPO}_{4}^{2-}$ can lead to the formation of $\mathrm{Ca}_{3}\left(\mathrm{PO}_{4}\right)_{2}$ insoluble substance in the hydration reaction of hemihydrate phosphogypsum, which significantly hindered the hydration reaction and prolonged the setting time of the paste. On the other hand, $\mathrm{HPO}_{4}^{2-}$ can change the crystallization habit of the hydration product of $\mathrm{CaSO}_{4} \cdot 2 \mathrm{H}_{2} \mathrm{O}$ and make it change from needle-columnar to semiflake and irregular shape, resulting in a significant reduction in the mechanical properties of the hardened paste.

\section{Data Availability}

The data used to support the findings of this study are available from the corresponding author upon request. 


\section{Conflicts of Interest}

The authors declare that they have no conflicts of interest.

\section{Acknowledgments}

This work has been vigorously supported by the Key Public Welfare Special Project of Henan Province (no. 201300311000).

\section{References}

[1] E. Saadaoui, N. Ghazel, C. Ben Romdhane, and N. Massoudi, "Phosphogypsum: potential uses and problems - a review," International Journal of Environmental Studies, vol. 74, no. 4, pp. 558-567, 2017.

[2] H. Tayibi, M. Choura, F. A. López, F. J. Alguacil, and A. López-Delgado, "Environmental impact and management of phosphogypsum," Journal of Environmental Management, vol. 90, no. 8, pp. 2377-2386, 2009.

[3] C. R. Cánovas, F. Macías, R. Pérez-López, M. Dolores Basallote, and R. Milan Becerro, "Valorization of wastes from the fertilizer industry: Current status and future trends," Journal of Cleaner Production, vol. 174, pp. 678-690, 2018.

[4] Q. Wang, Y. Cui, and J. Xue, "Study on the improvement of the waterproof and mechanical properties of hemihydrate phosphogypsum-based foam insulation materials," Construction and Building Materials, vol. 230, Article ID 117014, 2020.

[5] W. Cao, W. Yi, J. Peng, J. Li, and S. Yin, "Recycling of phosphogypsum to prepare gypsum plaster: effect of calcination temperature," Journal of Building Engineering, vol. 45, Article ID 103511, 2021.

[6] X. Chen, J. Gao, C. Liu, and Y. Zhao, "Effect of neutralization on the setting and hardening characters of hemihydrate phosphogypsum plaster," Construction and Building Materials, vol. 190, pp. 53-64, 2018.

[7] Z. Jin, B. Ma, Y. Su, H. Qi, W. Lu, and T. zhang, "Preparation of eco-friendly lightweight gypsum: use of beta-hemihydrate phosphogypsum and expanded polystyrene particles," Construction and Building Materials, vol. 297, Article ID 123837, 2021.

[8] X. Li and Q. Zhang, "Dehydration behaviour and impurity change of phosphogypsum during calcination," Construction and Building Materials, vol. 311, Article ID 125328, 2021.

[9] Y. Mi, D. Chen, and A. Wang, "Effects of phosphorus impurities on the preparation of $\alpha$-calcium sulfate hemihydrate from waste phosphogypsum with the salt solution method under atmospheric pressure," CrystEngComm, vol. 21, no. 16, pp. 2631-2640, 2019.

[10] J. S. Andrade Neto, J. D. Bersch, T. S. M. Silva, E. D. Rodríguez, S. Suzuki, and A. P. Kirchheim, "Influence of phosphogypsum purification with lime on the properties of cementitious matrices with and without plasticizer," Construction and Building Materials, vol. 299, Article ID 123935, 2021.

[11] B. Li, J. Shu, L. yang et al., "An innovative method for simultaneous stabilization/solidification of PO43- and F- from phosphogypsum using phosphorus ore flotation tailings," Journal of Cleaner Production, vol. 235, pp. 308-316, 2019.

[12] K. K. Sulfat-Polhidrata, "Effects of impurities from phosphogypsum on the crystal growth of calcium sulfate hemihydrates," Materiali in tehnologije, vol. 52, no. 5, pp. 633-637, 2018.

[13] H. Qi, B. Ma, H. Tan, Y. Su, W. Lu, and Z. Jin, "Influence of fluoride ion on the performance of PCE in hemihydrate gypsum pastes," Journal of Building Engineering, vol. 46, Article ID 103582, 2021.
[14] V. Vinnichenko and A. Riazanov, "Environmental problems of phosphogypsum utilization," Key Engineering Materials, Trans Tech Publications Ltd, vol. 864, , pp. 108-114, 2020.

[15] M. Singh, M. Garg, C. L. Verma, S. K. Handa, and R. Kumar, "An improved process for the purification of phosphogypsum," Construction and Building Materials, vol. 10, no. 8, pp. 597-600, 1996.

[16] L. Dvorkin, N. Lushnikova, M. Sonebi, and J. M. Khatib, "Properties of modified phosphogypsum binder," Academic Journal of Civil Engineering, vol. 35, no. 2, pp. 96-102, 2017.

[17] S. Zhou, X. Li, Y. Zhou, C. Min, and Y. Shi, "Effect of phosphorus on the properties of phosphogypsum-based cemented backfill," Journal of Hazardous Materials, vol. 399, Article ID 122993, 2020.

[18] Y. Ennaciri, I. Zdah, H. El Alaoui-Belghiti, and M. Bettach, "Characterization and purification of waste phosphogypsum to make it suitable for use in the plaster and the cement industry," Chemical Engineering Communications, vol. 207, no. 3, pp. 382-392, 2020.

[19] R. Moalla, M. Gargouri, F. Khmiri, L. Kamoun, and M. Zairi, "Phosphogypsum purification for plaster production: a process optimization using full factorial design," Environmental Engineering Research, vol. 23, no. 1, pp. 36-45, 2018.

[20] I. V. Fornés, D. Vaičiukynienè, D. Nizevičienè, V. Dorosevas, and K. Dvorak, "A method to prepare a high-strength building material from press-formed phosphogypsum purified with waste zeolite," Journal of Building Engineering, vol. 34, Article ID 101919, 2021.

[21] X. Chen, J. Gao, and Y. Zhao, "Investigation on the hydration of hemihydrate phosphogypsum after post treatment," Construction and Building Materials, vol. 229, Article ID 116864, 2019.

[22] Y. Zhang, J. Yang, and X. Cao, "Effects of several retarders on setting time and strength of building gypsum," Construction and Building Materials, vol. 240, Article ID 117927, 2020. 